Article

\title{
The Paris Agreement: Destined to Succeed or Doomed to Fail?
}

\author{
Oran R. Young \\ Bren School of Environmental Science and Management, University of California, Santa Barbara, CA 93106-5131, USA; \\ E-Mail: oran.young@gmail.com
}

Submitted: 1 April 2016 | Accepted: 20 May 2016 | Published: 8 September 2016

\begin{abstract}
Is the 2015 Paris Agreement on climate change destined to succeed or doomed to fail? If all the pledges embedded in the intended nationally determined contributions (INDCS) are implemented fully, temperatures at the Earth's surface are predicted to rise by $3-4{ }^{\circ} \mathrm{C}$, far above the agreement's goal of limiting increases to $1.5^{\circ} \mathrm{C}$. This means that the fate of the agreement will be determined by the success of efforts to strengthen or ratchet up the commitments contained in the national pledges over time. The first substantive section of this essay provides a general account of mechanisms for ratcheting up commitments and conditions determining the use of these mechanisms in international environmental agreements. The second section applies this analysis to the specific case of the Paris Agreement. The conclusion is mixed. There are plenty of reasons to doubt whether the Paris Agreement will succeed in moving from strength to strength in a fashion resembling experience with the Montreal Protocol on ozone depleting substances. Nevertheless, there is more room for hope in this regard than those who see the climate problem as unusually malign, wicked, or even diabolical are willing to acknowledge.
\end{abstract}

\section{Keywords}

commitments; INDCs; Montreal Protocol; national pledges; Paris Agreement; ratcheting up

\section{Issue}

This article is part of the issue "Climate Governance and the Paris Agreement", edited by Jon Hovi and Tora Skodvin (University of Oslo, Norway).

(C) 2016 by the author; licensee Cogitatio (Lisbon, Portugal). This article is licensed under a Creative Commons Attribution 4.0 International License (CC BY).

\section{Introduction}

Opinions differ sharply regarding the fate of the agreement on climate change adopted on 12 December 2015 at the close of the Conference of the Parties to the UN Framework Convention on Climate Change (UNFCCC COP 21) in Paris (UNFCCC, 2015). Those who are optimistic about the Paris Agreement point to: (i) the explicit reference to the desirability of limiting temperature increases to $1.5^{\circ} \mathrm{C}$, (ii) the inclusion of Intended Nationally Determined Contributions (INDCs) for most countries rather than just those developed countries listed in Annex 1 of the UNFCCC, (iii) the legal character of the agreement, and (iv) the commitment to review pledges periodically with a view toward strengthening them over time. Pessimists, by contrast, note that (i) national INDCs are often vague, highly as- pirational, and fundamentally unenforceable, (ii) the provisions dealing with monitoring, reporting, and verification are far from watertight, (iii) the mechanism regarding support for developing countries is underdeveloped, and (iv) the agreement lacks explicit compliance mechanisms. So, the question is: Does the Paris Agreement represent a major step forward by comparison with the outcome of COP 15 in 2009 or is this new agreement simply the Copenhagen Accord redux or, worse yet, Copenhagen lite?

There is one thing we can say with certainty. The national pledges that countries have made in the INDCs they submitted in preparation for the Paris negotiations are not sufficient to prevent a rise in temperatures at the Earth's surface beyond $2{ }^{\circ} \mathrm{C}$, much less beyond $1.5^{\circ} \mathrm{C}$, even if all parties implement their pledges fully and faithfully. Even optimistic assessments of the 
pledges conclude that their fulfillment would lead to temperature increases on the order of $3.5{ }^{\circ} \mathrm{C}$ (see Figure 1). This means that the critical determinant of the success of the Paris Agreement will be whether the agreement sets in motion a process that leads step-bystep and sooner rather than later to what analysts describe as a ratcheting up of the pledges embedded in the INDCs. Realistically, to achieve the target articulated in Art. 2(1) of the Paris Agreement (UNFCCC, 2015), the major emitters (China, the United States, the European Union, India) would need to raise their pledges to reduce emissions substantially or, in some cases, to commit to making serious reductions by 2025 or by 2030 at the latest. At the same time, other countries (especially important ones like Brazil, Indonesia, Japan, and Russia) would need to avoid taking steps that would exacerbate the problem. Is this within the realm of the possible?

In this article, I take up this question and examine it from several angles. I start by identifying the mechanisms through which the commitments of individual members of international regimes can be strengthened. I then consider the conditions likely to determine the success or failure of efforts to make use of these mechanisms to strengthen international commitments in specific cases. With the insights generated from this analysis in hand, I turn to the question of whether the
Paris Agreement is destined to succeed or doomed to fail. In assessing the link between general observations about ratcheting up international commitments and the specific case of the climate regime, I draw on a number of lines of analysis, including several arguments that Arild Underdal has played a key role in developing over the course of his career (Underdal, 2002, $2008,2010)$. In conclusion, I offer a tentative response to the question posed in the article's title.

\section{Strengthening International Regimes: Mechanisms and Conditions}

International regimes commonly (perhaps even typically) start out as relatively modest arrangements that do not make demands on their members that will prove difficult to implement. Some go from strength to strength, adopting more ambitious commitments and becoming increasingly effective over time. But others do not grow stronger with the passage of time. The Montreal Protocol on ozone-depleting substances (ODSs), often thought of as the gold standard in these terms, has been able to ratchet up commitments both by accelerating phaseout schedules for those chemicals already covered and by adding more chemicals to the list of those covered under the terms of the agreement (Andersen \& Sarma, 2002; Parson, 2003). Although the

\section{Climate Scoreboard}

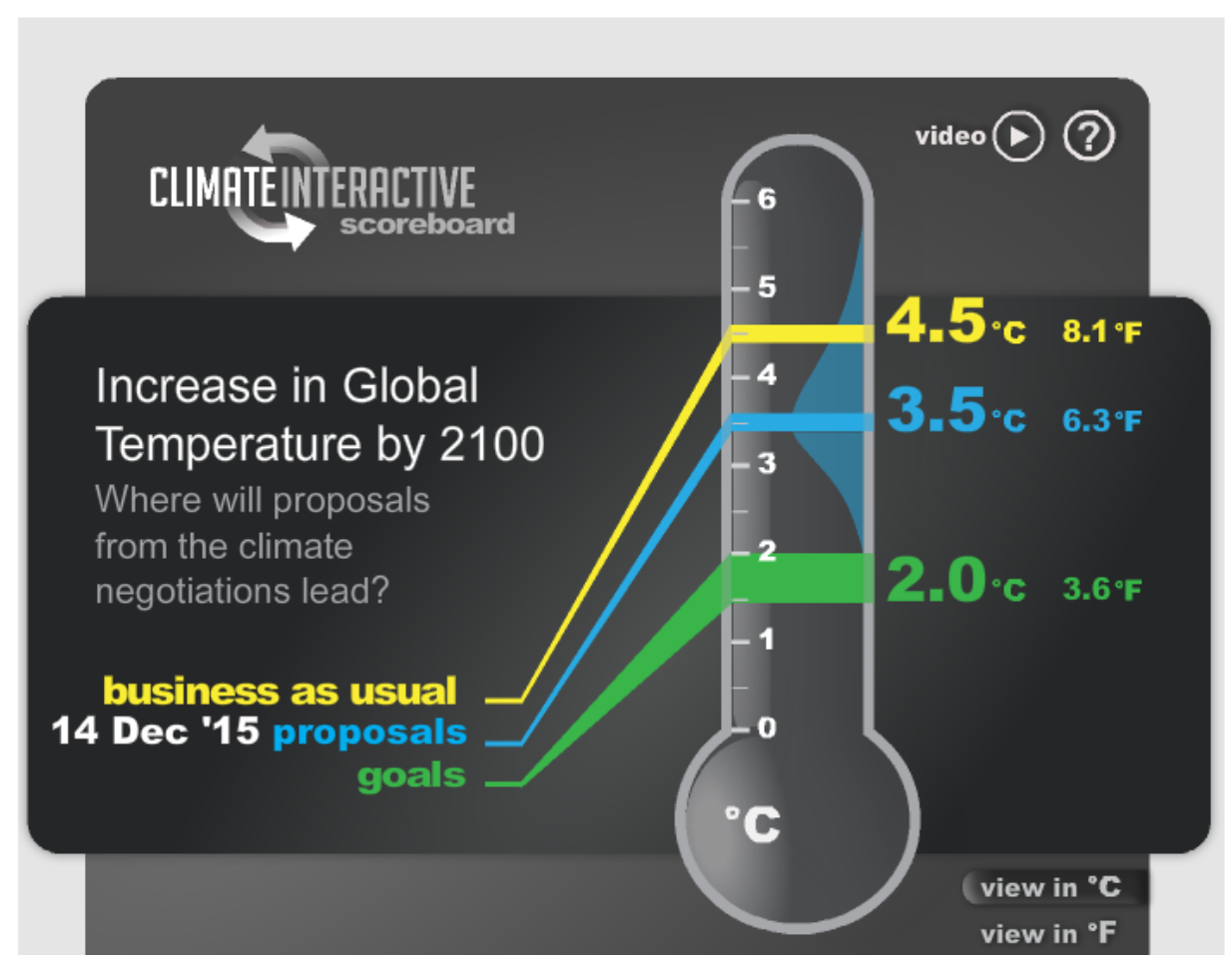

Figure 1. Temperature increases as a function of greenhouse gas emissions. Source: Climatelnteractive (www.climateinteractive.org/tools/scoreboard). 
stratospheric ozone layer still shows signs of the impacts of ODSs, the problem of ozone depletion is well on its way to being solved. By contrast, few if any countries were prepared to ratchet up their commitments to reducing greenhouse gas emissions under the terms of the Kyoto Protocol at the close of the first commitment period in 2012. Several parties had withdrawn from the protocol entirely; those that remained were in no mood to accept more stringent reduction targets. This suggests that the trick is to craft arrangements allowing for step-by-step strengthening of initial commitments and to muster the political will needed to make use of these procedures effectively. This leads to a review of various mechanisms that can play this role followed by an examination of the conditions governing success in efforts to make use of these mechanisms.

\subsection{Mechanisms}

There are a number of distinct mechanisms that can produce a progressive dynamic regarding the strength of commitments embedded in international governance systems. Not all regimes are alike in this regard. The relevance of specific mechanisms depends both on the nature of the problem at stake and the general character of the regime created to deal with it. In the final analysis, individual cases must be considered on their own terms. Nevertheless, some concrete examples will serve to provide an overview of the range of mechanisms available in this context.

One of the simplest mechanisms for ratcheting up commitments is to grant authority to the conference/meeting of the parties to amend existing provisions without requiring formal ratification on the part of the member states. Under the 1987 Montreal Protocol on Substances that Deplete the Ozone Layer, for example, the Meeting of the Parties has acted repeatedly to accelerate phaseout schedules for individual ODSs, as it has become clear that more ambitious goals have entered the realm of what is economically and politically feasible. Similarly, the International Maritime Organization, acting as the agency responsible for the 1973/1978 International Convention for the Prevention of Pollution from Ships (MARPOL), can make decisions involving amendments to the convention's annexes dealing with various types of discharges (e.g. noxious substances, sewage, garbage). These decisions are assumed to become legally binding on member states that do not object to them within a specified period of time.

Another mechanism involves adding chemicals or other substances to the list of those banned or controlled under the terms of an international regime. Adding new families of chemicals to the list of those scheduled for phaseout under the Montreal Protocol, for instance, requires not only a decision on the part of the MOP but also acceptance on the part of member states. This is a more stringent requirement. But it need not be a barrier to strengthening commitments. The Montreal Protocol now covers almost 100 hazardous chemicals. A similar mechanism occurs in the case of the 2001 Stockholm Convention on Persistent Organic Pollutants. At the outset, the convention focused on banning or limiting the use of the so-called "dirty dozen" (e.g. chlordane, dieldrin, heptachlor). But there are thousands of industrial chemicals that belong to the category of persistent organic pollutants (POPs); more are being developed all the time. The convention sets up a Persistent Organic Pollutants Review Committee to make recommendations to the parties regarding the elimination or regulation of additional POPs. In fact, the parties have added chemicals to the list of regulated POPs on several occasions, though this has proved to be a complex and difficult mechanism to use successfully under the terms of the Stockholm Convention.

A different mechanism comes into play where the parties initially establish a framework convention that becomes a constitutive platform on which to develop protocols dealing with a variety of more specific concerns. A prominent case is the 1979 Geneva Convention on Long-range Transboundary Air Pollution (LRTAP). Operating under the auspices of the UN Economic Commission for Europe, LRTAP has spawned seven protocols dealing initially with key pollutants like sulfur and nitrogen but expanding over time to encompass a range of additional pollutants including volatile organic compounds, heavy metals, and persistent organic pollutants. While this mechanism requires parties to agree to individual protocols on a case-by-case basis, it has the virtue of allowing parties to make progress in dealing with specific pollutants without renegotiating constitutive or foundational arrangements or waiting until the member states are prepared to agree on the terms of measures dealing with a sizable collection of pollutants taken together.

Yet another mechanism for strengthening commitments occurs in regimes that establish procedures for setting quotas or allowable harvest levels for harvesting of living resources. What is known as the schedule under the 1946 International Convention for the Regulation of Whaling provides a prominent example. In the early years, the parties adopted relatively high annual quotas to avoid forceful opposition on the part of key whaling states, despite the objections of both scientists and environmentalists concerned about declining stocks of great whales. Over time, however, the International Whaling Commission took decisions to lower the quotas step-by-step. In 1982, the commission adopted a moratorium on whaling by setting the quotas for individual species at zero. Initially presented as an arrangement that would last for ten years, the commission has never been able to muster the threefourths majority required to reach agreement on the replacement of the moratorium with some alternative system for setting quotas. In effect, this mechanism in- 
volves a process of ratcheting down quotas in contrast to the effort to ratchet up commitments in the context of regimes dealing with air pollution.

A mechanism that is often deployed in conjunction with other mechanisms centers on the provision of financial assistance to member states that agree to strengthen their commitments under the terms of a particular regime. Financial arrangements may be embedded within the provisions of individual regimes or take the form of external mechanisms that can provide assistance to those willing to strengthen their commitments under a particular regime. A prominent example of the first option is the Montreal Protocol Multilateral Fund, added to the regime under the terms of a 1990 amendment as a means of helping developing countries (known as Art. 5 parties) to shift to non-ODSs or to pursue development without relying on ODSs. The Global Environment Facility (GEF) provides an example of the second option. The GEF is a separate body sponsored jointly by the UN Development Programme, the UN Environment Programme, and the World Bank. The Facility serves as a financial mechanism for a number of conventions, including the 1992 Convention on Biological Diversity, the 1995 Convention to Combat Desertification, and the 2013 Minamata Convention on Mercury as well as the UNFCCC and the Stockholm Convention. The point of this mechanism is to strengthen commitments associated with specific regimes by providing ways to alleviate financial problems that may make it hard for parties to live up to commitments they have made or to accept new commitments regarding specific problems.

\subsection{Conditions}

Thus, numerous mechanisms are available to those seeking to strengthen commitments embedded in international regimes. The selection of a mechanism for strengthening commitments in a specific case will depend on the character of the regime in question. Accelerating phaseout schedules for individual chemicals is one thing; reducing quotas for harvested species is another. At the same time, it is important to note that the selection of a suitable mechanism for strengthening commitments does not guarantee success. Some international environmental regimes do make a significant contribution to problem solving (Underdal, 2008). Although many observers regard the ozone regime as the gold standard in these terms, there are other success stories, including the Antarctic Treaty System and the combination of agreements dedicated to cleaning up the Rhine River. Still, governance failure is common in this realm. Even in the case of ozone, drastic reductions in the production and consumption of ODSs have yet to eliminate annual ozone holes, particularly in the high latitudes.

This makes it essential to think about conditions likely to determine the success or failure of efforts to make use of strengthening mechanisms in connection with specific regimes. What is it that produces success in ratcheting up commitments in some regimes but failure in other cases? Clearly, complex causality is the order of the day in this context. Numerous conditions, typically interacting with one another, come into play in determining outcomes in specific cases. Even so, it is possible to identify some key conditions that are relevant to efforts to strengthen a variety of specific regimes.

Regimes may incorporate provisions automatically strengthening commitments over the course of time. An agreement calling for additional reductions in a given pollutant every five or ten years in the absence of a decision to the contrary, for instance, exemplifies this possibility. But at the international level, there are few examples of arrangements of this sort. The course of least resistance is almost always to maintain the status quo until and unless an explicit decision is taken to strengthen existing commitments. This creates a bias against the operation of the sorts of mechanisms described in the preceding subsection. Policy agendas are always crowded, and political capital is limited (Kingdon, 1995). Once a concerted effort is made to establish specific commitments to address a given problem, there is a natural tendency for policymakers to move on to address other issues clamoring for attention on relevant policy agendas. Nevertheless, ratcheting up does occur in some cases. So, the question becomes: What does it take to overcome the force of inertia or path dependence in situations of this sort? Are there specific conditions that are sufficient to overcome this natural tendency toward stasis?

One prominent example centers on the configuration of the interests of a regime's member states. In cases where there are clear asymmetries in the sense that some members stand to benefit from strengthening commitments while others expect to lose, any effort to ratchet up initial commitments will prove difficult, requiring hard bargaining at a minimum. Even in cases where all parties can expect to benefit from ratcheting up commitments, what Underdal has described as the law of the least ambitious program may make progress slow (Underdal, 1981). That is, it is hard to proceed more quickly than those who are reluctant to embrace new commitments are willing to move. In real world cases, things are apt to become considerably more complex. Individual members may benefit from the implementation of some features of a regime, while losing from the implementation of others. Uncertainty may make it difficult to determine the incidence of benefits and costs, a factor that leaves a lot of room for the application of competing but untestable narratives or ideologies on the part of those responsible for ratcheting up commitments. Vigorous debates regarding such matters may occur among policymakers within individual regime members. In situations of this kind, 
seemingly authoritative reports about the impacts of a particular problem can have a big impact. Reports regarding the probable health impacts of the loss of stratospheric ozone appearing during the mid-1980s, for example, had a dramatic effect on the negotiations leading initially to agreement on the terms of the 1987 Montreal Protocol and subsequently to agreement on amendments accelerating phaseout schedules for a variety of ODSs. Current reports documenting the health impacts of the airborne particulates known as PM2.5, especially in major players like China, may play a parallel role in the ongoing debates about efforts to control severe air pollution.

Beyond this lies the influence of particularly influential actors or what we can think of as "veto players" located or based within individual member states. In the case of ozone depletion, the decision by DuPont, an American chemical company that produced ODSs accounting for some $25 \%$ of the global market in the mid-1980s, to become an active supporter of phasing out many chlorofluorocarbons and halons made a big difference in efforts to accelerate phaseout schedules under the terms of the Montreal Protocol. Conversely, veto players may emerge as entrenched sources of opposition to efforts to strengthen national commitments under the terms of specific regimes, especially in cases where such players are in a position to exercise direct influence over policymaking processes at the national level. The example of the coal industry is particularly interesting in this connection. Whereas there is some reason to believe that the industry is losing strength as a veto player in China, it is hard to find evidence of such a decline in the United States. The US Supreme Court's unprecedented February 2016 order suspending the implementation of the regulations associated with President Obama's Clean Power Plan pending a final determination regarding the legality of these regulations is a striking indicator of the ability of the coal industry to wield influence over the American policymaking process (Liptak \& Davenport, 2016).

Shifts in the fortunes of relevant industries may also affect efforts to strengthen commitments regarding specific environmental problems. In 1946 at the time of the negotiation of the International Convention for the Regulation of Whaling, for example, most member states had an active and influential whaling industry. But with the passage of time, substitutes for whale products developed for most uses, and whaling became a dying industry. By 1982, when the International Whaling Commission adopted the moratorium on harvesting great whales, many key states (e.g. Australia, the Netherlands, the UK, the US) no longer had active whaling industries. Today, even the Japanese whaling industry is a vestige of its former self, though the government of Japan continues to fight a rearguard action against anti-whaling forces. Whale-watching, a new industry that has a powerful interest in keeping whales alive, has become increasingly influential in many of the regime's member states. Under the circumstances, the 1982 decision to strengthen commitments by setting quotas to zero was much easier in political terms than it would have been in earlier times. Interestingly, the three-fourths decision rule has served as an effective barrier to the success of efforts to reverse or amend the 1982 decision. The case of whaling is undoubtedly an extreme example. But it is not unique. Shifts in the structure of those industries that have major stakes in the concerns of specific regimes can play a key role in determining the fate of efforts to strengthen commitments.

Another condition centers on the magnitude and the incidence of the costs involved in taking the actions required to solve the problems that regimes address. Costs are difficult both to calculate in advance and to document over time. But a common occurrence in this context is that the actual costs of solving environmental problems turn out to be a fraction of the costs projected by opponents during the negotiations leading to the creation of regimes in the first place. This is partly a matter of the politics of environmental negotiations. Those who are opposed to the creation of a regime regularly exaggerate the costs that will be involved in efforts to implement the terms of a proposed agreement. In part, however, it is a matter of technological innovation. Once a regime is in place and those whose actions are affected focus their attention on the process of implementation, innovations begin to emerge that make compliance with the terms of a regime less costly than initially expected. Once again, the ozone regime provides a clearcut example. Not only did producers find affordable alternatives for many uses of ODSs; the alternatives sometimes turned out to be more cost effective than the chemicals they replaced. When this occurs, it becomes easier, sometimes dramatically easier, to strengthen commitments that had been the subject of hard bargaining at the outset.

Another condition that comes into play in some settings involves the content, intensity, and arousal of public concern. Sometimes this is a matter of more or less far-reaching shifts in public attitudes and values. It is hard to deny, for example, that a broad swath of the public has come to accept the proposition that nonhuman species are sentient beings endowed with a right to life, a normative position that complicates the situation of industries that are predicated on the consumptive use of animals. Obviously, there are limits to this line of thinking; no one advocates acknowledging a right to life for disease-bearing insects. But in the cases of charismatic megafauna (e.g. elephants, polar bears, whales), shifting public attitudes have played an important role in strengthening the arguments of those favoring the tightening of the rules embedded in regimes dedicated to the conservation of wildlife (Safina, 2015). In extreme cases, the force of this development 
has triggered a shift from conservation (e.g. achieving maximum sustainable yields on an ongoing basis) to preservation (e.g. minimizing all intentional killing of individual members of key species) as the fundamental goal of relevant regimes.

In other cases, the role of public attitudes is more a matter of framing issues in such a way as to tap into intense concerns that can lead to the mobilization of public interest in an issue and the growth of pressure on policymakers to take action to address specific problems. In many societies, success in framing an issue as a matter of public health can have this effect. Turning to the example of ozone depletion again, it is hard to overestimate the importance of the specter of a dramatic rise in the incidence of melanomas and glaucoma arising from increased exposure to solar radiation caused by the seasonal thinning of the stratospheric ozone layer. Balanced assessments of benefits and costs may or may not favor the case of those calling for the ratcheting up of commitments that lie at the heart of environmental regimes. But success in framing issues in ways that activate deeply held and intense public concerns can make a critical difference to the outcome of efforts to strengthen commitments embedded in specific regimes.

Cutting across these concerns is the role of leadership or what some analysts refer to as championship as a condition affecting efforts to strengthen the commitments of environmental regimes (Litfin, 1994). Leadership can take a number of forms (Young, 1991). Intellectual leadership is a matter of creativity in finding new and effective ways to characterize a problem. Entrepreneurial leadership involves the ability to put together coalitions of the willing to support the strengthening of international commitments. Structural leadership centers on the capacity to bring to bear material resources (e.g. financial assistance or rewards) in a manner that helps to persuade reluctant parties to join coalitions supporting the strengthening of commitments. In all its forms, leadership can be idiosyncratic. It is hard to forecast the emergence of effective leaders in a given issue area, much less to predict whether their efforts will succeed in bringing about major advances in the strength of commitments in specific cases. Nevertheless, case studies show repeatedly that leaders play key roles with regard to the evolution of those regimes that do become stronger with regard to the content and extent of their commitments.

It is easy to identify synergies regarding the operation of many of these conditions. When relative symmetry in the interests of member states is combined with veto players willing to engage actively in problemsolving behavior and with technological advances that lower the costs of addressing a problem significantly, for example, there are good reasons to be optimistic. If effective leadership emerges in such cases, there is all the more reason to anticipate success. A combination of this sort accounts for the success of the ozone re- gime, widely regarded as the preeminent example when it comes to the progressive development of stronger commitments needed to solve a major international problem.

\section{Strengthening the Paris Agreement}

Many observers regard the problem of climate change as particularly intractable in these terms. They see climate change as what Underdal and his colleagues have called a malign problem and what others have characterized as a wicked or diabolical problem that does not lend itself to progress in the form of strengthening commitments over time (Miles et al., 2002; Steffen, 2011). But this intuitively appealing assessment needs to be subjected to critical evaluation. What light does the preceding section's analysis of mechanisms and conditions shed on prospects for strengthening international commitments regarding climate and, more specifically, on the likely fate of the Paris Agreement?

The mechanisms for strengthening commitments embedded in the Paris Agreement are considerably less straightforward than those described in the preceding section. Strengthening must take the form, first and foremost, of ratcheting up the commitments articulated in the INDCs. But this is hardly a matter of simply accelerating phaseout schedules as in the case of ozone depletion, adding chemicals to the proscribed list as in the case of persistent organic pollutants, or changing quotas as in the case of whaling. There is no common currency underlying the INDCs as formulated by individual countries. Each country has formulated its INDC in its own terms. Even in cases where they refer to quantified reductions in greenhouse gas (GHG) emissions, there are different base years and different procedures for measuring or verifying progress. Whereas the European Union has pledged to reduce domestic emissions across the full set of 28 member countries by $40 \%$ relative to the base year of 1990 by 2030, for example, the United States has promised to reduce emissions by $26-28 \%$ relative to the base year of 2005 by 2025 . And some of the INDCs are not formulated in terms of quantified reductions at all. China, for instance, has pledged to reach peak GHG emissions no later than 2030, to make a good faith effort to begin to reduce emissions sooner, and, in the meantime, to reduce the carbon intensity of goods and services by $60-65 \%$ relative to 2005 by 2030 . India has promised to lower energy intensity by $33-35 \%$ relative to 2005 by 2030 and to increase the proportion of non-fossil fuel based power generation to $40 \%$ by 2030 . Under the circumstances, strengthening the INDCs would amount to a collection of national formulas that would not be easy to evaluate in aggregate terms.

A second mechanism for strengthening commitments embedded in the Paris Agreement involves the provision of funding to help developing countries to 
find ways to grow their economies without increasing emissions of GHGs and to adapt to the impacts of climate change. But here, too, it is difficult to understand exactly what the strengthening of commitments would entail. In some respects, the terms of the Paris Agreement regarding funding backtrack from the commitments articulated in the 2009 Copenhagen Accord. In Copenhagen, the parties pledged to mobilize new and additional funding approaching $\$ 30$ billion during 2010-2012 and to make an effort to raise this to $\$ 100$ billion per year by 2020. By contrast, the Paris Agreement says simply that "[d]eveloped country Parties shall provide financial resources to assist developing country Parties with respect to both mitigation and adaptation in continuation of their existing obligations under the Convention" (Art. 9.1). The developed countries are clearly expected to increase their contributions along these lines over time. But because there is no explicit baseline regarding the scale of these contributions, it is difficult to say what a strengthening of the commitments regarding funding would entail.

One way to think about the Paris Agreement is to treat it as a system of pledge and review. The parties agree to engage in what the agreement describes as a "global stocktake" from time to time in order "to assess collective progress towards achieving the purpose of this Agreement" with the intention of strengthening their commitments as needed to fulfill the goals of the agreement (Art. 14). They plan to "undertake the first global stocktake in 2023 and every five years thereafter unless otherwise decided by the Conference of the Parties serving as the meeting of the Parties to the Paris Agreement" (Art. 14.2). Informally, there has been discussion of accelerating this schedule, carrying out the first of these assessments as early as 2020 .

This is a hopeful sign with regard to the prospects for strengthening commitments under the Paris Agreement. As evidence regarding the reality of climate change becomes more clearcut and undeniable, the parties may realize that they must make a good faith effort to strengthen their commitments. Still, it would be risky to set too much store by this mechanism. If key countries (e.g. China and the United States) take the lead, others may feel an obligation to follow suit. But there is nothing mandatory about the pledge and review process. Efforts to strengthen the commitments of the Paris Agreement through this process could easily break down in mutual recriminations, with individual parties accusing each other of bad faith due to their failure to take strong stands in favor of strengthened commitments needed to fulfill the goal of holding temperature increases to $2{ }^{\circ} \mathrm{C}$, much less the more demanding goal of holding the line at $1.5^{\circ} \mathrm{C}$.

What, then, of the conditions that will determine whether there is progress toward strengthening the Paris commitments during the coming years? Is the problem of climate change extremely malign, diaboli- cal, or super-wicked as many observers have suggested? The case for answering this question in the affirmative rests on several distinct propositions. Energy derived from fossil fuels is deeply embedded in all aspects of industrialized economies. The principal beneficiaries of this system (e.g. the coal companies, the multinational oil companies) wield enormous power in major political systems that allows them to stymie efforts to transition away from dependence on fossil fuels. The character of climate change as a collective-action problem encourages individual countries to hang back, waiting to see if others will take the lead before adopting major steps to address the problem on their own.

Still, this reasoning is by no means the whole story regarding efforts to address the problem of climate change. The configuration of national interests relating to climate change is not as antithetical to progress as in the case of truly asymmetrical situations where one party's gains are matched by another party's losses. Everyone stands to lose from severe changes in the Earth's climate system (though not necessarily to the same extent), and everyone stands to benefit from maintaining what analysts now call a "safe operating space for humanity" (Rockström et al., 2009). As with all collective-action problems, it may prove difficult to induce key states to act as first movers when it comes to reducing GHG emissions. But as the recent collaborative initiatives of China and the United States (together accounting for over $40 \%$ of global emissions) suggest, leadership on the part of key states in this realm is not beyond the realm of the possible. More generally, this may be a case that lends itself to treatment in terms of what Schelling calls a "k group" or a like-minded coalition of leading players (Schelling, 1978). Certainly, a coalition encompassing China, the European Union, India, and the United States could put the international community on a path toward solving the problem of climate change.

Veto players within individual member states (e.g. coal companies, oil companies) are able to exert great influence regarding the fate of efforts to take effective steps to curb GHG emissions. The political power of the coal interests in opposing President Obama's Clean Power Plan, for example, offers a compelling recent illustration of this proposition. But it would be a mistake to exaggerate the significance of veto players. It is probable that the actual costs of reducing GHG emissions will turn out to be much lower than the projections made by opponents of current policy initiatives (Stern, 2009). Technological innovations are likely to prove highly important, and there is every reason to expect that many new companies will arise that stand to make profits from the production and distribution of alternative sources of energy. Firm commitments to the reduction of GHG emissions may trigger a dynamic under which those who are able to profit from this development gain the upper hand. 
The critical factor may turn out to be shifts in public attitudes and values or what some have characterized as the rise of a new consciousness regarding humanenvironment relations. So long as environmental issues in general and climate change in particular remain matters of marginal concern to broad segments of the public in key countries, those who stand to gain from opposing serious efforts to reduce GHG emissions are likely to be able to maintain a stranglehold over policy initiatives needed to make a difference regarding the problem of climate change. But an aroused public in a few key countries might change this picture dramatically. How might such a development come about? One possibility is some sort of climate shock that jolts wide swaths of the public into taking climate change seriously. A less dramatic possibility is the development over time of a social movement that succeeds in framing climate change in compelling terms (perhaps as a public health crisis) and in finding ways to mobilize opinion leaders within various strata of the population (McKibben, 2013). Will some such development occur during the foreseeable future? It is difficult to provide a straightforward answer to this question. But it is well within the realm of the possible that what seems like a malign or even a wicked or diabolical problem today will give way to far-reaching social changes that produce profound alterations in our understanding of the nature of this seemingly intractable problem.

\section{Conclusion: And the Answer Is...?}

So, is the Paris Agreement destined to succeed or doomed to fail? The critics of the agreement have a strong case. Temperatures at the Earth's surface have already risen by an average of $1{ }^{\circ} \mathrm{C}$. The mechanisms for strengthening commitments under the terms of the agreement seem ill-defined and weak. As the recent experiences of the United States make clear, efforts to implement the pledges embedded in the INDCs may run into serious roadblocks within individual member countries. In many cases, it will not be easy to monitor or verify the actual progress of individual countries. The review procedure sketched out in the Paris Agreement may prove ineffective. In the absence of a real sense of crisis, the global stocktake procedure may prove desultory and generally unpersuasive. Thus, it would not be surprising if the Paris Agreement becomes another in a long list of failed attempts to come to terms with the problem of climate change.

Yet I do not want to end this essay with a simple statement that the Paris Agreement is doomed to fail. There is no basis for making firm predictions about such matters. But in thinking about pathways to success for the agreement, I believe we need to differentiate two distinct scenarios. One scenario features a severe climate shock, something far more disruptive than hurricanes Katrina or Sandy. Think of events on the or- der of the disintegration of the Greenland Ice Sheet or the shutting down of the thermohaline circulation in the North Atlantic as possibilities (Lenton et al., 2008). Shocks or crises of this magnitude create rare windows of opportunity during which far-reaching changes in institutional arrangements can occur at what seems like lightning speed compared with normal times. Such windows do not stay open long, and it is essential to be prepared for such opportunities with well-developed options that can be put into place quickly. While we cannot estimate the probability of a shock of this magnitude occurring in the next decade or two with precision, I regard this scenario as plausible. It is well worth taking seriously in planning for the future. Under the right circumstances, the Paris Agreement might thrive in the wake of such a crisis.

The other scenario focuses on the prospects for the success of the Paris Agreement in the absence of a severe climate shock. The critical issues here, in my judgment, involve efforts to break the political grip of the forces of business as usual (and especially the fossil fuel industry) and to foster a revolution in public consciousness in which new attitudes and values regarding human well-being take hold on a widespread basis. Breaking the grip of entrenched industries is difficult. But as Oreskes and Conway have shown, it can be done (Oreskes \& Conway, 2010). Particularly important in this regard is the promotion of shifts in underlying perspectives and attitudes of the sort that Pope Francis has articulated in his 2015 encyclical entitled Laudato si' (Laudato Si, 2015). What is at stake here is the transformation of our vision of the good life rather than the selection of one or another policy instrument on the basis of calculations of benefits and costs. It is easy to become cynical about the prospects for real change in situations of this sort. But fundamental shifts of this type do occur under some conditions, and it may well be that developments of this sort will determine the fate of the Paris Agreement.

\section{Acknowledgments}

My thinking on this subject has been stimulated by a series of annual workshops taking place at the School of Public Policy and Management, Tsinghua University, Beijing, China.

\section{Conflict of Interests}

The author declares no conflict of interests.

\section{References}

Andersen, S. O., \& Sarma, K. M. (2002). Protecting the ozone layer: The United Nations history. London: Earthscan Publications.

Kingdon, J. W. (1995). Agendas, alternatives, and public 
policies (2nd ed.). New York: Harper Collins.

Laudato Si. (2015). Laudato Si': The encyclical of Pope Francis on the environment. Retrieved from https:// laudatosi.com/watch

Lenton, T., Held, H., Kriegler, E., Hall J. W., Lucht, W., Rahmstorf, S., \& Schellnhuber, H. J. (2008). Tipping elements in the Earth's climate system. Proceedings of the National Academy of Sciences, 105, 17861793.

Liptak, A., \& Davenport, C. (2016, February 9). Supreme Court deals blow to Obama's effort to regulate coal emissions. New York Times. Retrieved from http:// www.nytimes.com/2016/02/10/us/politics/supreme -court-blocks-obama-epa-coal-emissions-regulations .html?_r=0

Litfin, K. T. (1994). Ozone discourses: Science and politics in global environmental cooperation. New York: Columbia University Press.

McKibben, B. (2013). Oil and honey: The education of an unlikely activist. New York: Times Books.

Miles, E. L., Underdal, A., Andresen, S., Wettestad, J., Skjaerseth, J. B., \& Carlin, E. M. (2002). Environmental regime effectiveness: Confronting theory with evidence. Cambridge: MIT Press.

Oreskes, N., \& Conway, E. M. (2010). Merchants of doubt: How a handful of scientists obscured the truth on issues from tobacco smoke to global warming. New York: Bloomsbury Press.

Parson, E. A. (2003). Protecting the ozone layer: Science and strategy. New York: Oxford University Press.

Rockström, J., Steffen, W., Noone, K., Persson, A., Chapin, S. F. III., Lambin, E., . . . Foley, J. (2009). Planetary boundaries: Exploring the safe operating space for humanity. Ecology and Society, 14(2), art. 32.
Safina, C. (2015). Beyond words: What animals think and feel. New York: Henry Holt and Company.

Schelling, T. C. (1978). Micromotives and macrobehavior. New York: W. W. Norton.

Steffen, W. (2011). A truly complex and diabolical policy problem. In J. S. Dryzek, R. B. Norgaard, \& D. Schlosberg (Eds.), The Oxford handbook of climate change and society (pp. 21-37). Oxford: Oxford University Press.

Stern, N. (2009). The global deal: Climate change and the creation of a new era of progress and prosperity. New York: Public Affairs.

Underdal, A. (1981). Politics of international fisheries management. Oslo: Universitetsforlaget.

Underdal, A. (2002). One question, two answers. In E. L. Miles, Environmental regime effectiveness (pp. 3-45). Cambridge: MIT Press.

Underdal, A. (2008). Determining the causal significance of institutions: Accomplishments and challenges. In O R. Young, L. A. King, \& H. Schroeder (Eds.), Institutions and environmental change (pp. 49-78). Cambridge: MIT Press.

Underdal, A. (2010). Complexity and challenges of longterm environmental governance. Global Environmental Change, 20, 386-393.

United Nations Framework Convention on Climate Change (UNFCCC). (2015). Paris Agreement. Retrieved from http://unfccc.int/documentation/docu ments/advanced_search/items/6911.php?priref=600 008831

Young, O. R. (1991). Political leadership and regime formation: On the development of institutions in international society. International Organization, 45, 281308.

\section{About the Author}

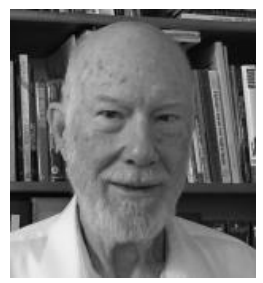

Oran R. Young is Professor Emeritus at the Bren School of Environmental Science and Management, University of California (Santa Barbara). His theoretical work deals with the role of social institutions in addressing problems of governance. He does applied work on atmospheric issues, the oceans, and the polar regions. The author of many books, his most recent work is Governing Complex Systems: Social Capital for the Anthropocene, forthcoming from MIT Press. 